\title{
The Issue of Calculating Elliptic Trajectories
}

\author{
Alexander Lozhkin ${ }^{1}$, Ivan Abramov¹, Pavol Bozek², Yuri Nikitin ${ }^{1}$ \\ ${ }^{1}$ Departments "Software" and "Mechatronic Systems", M.T. Kalashnikov Izhevsk State Technical University, Studencheskaya St. 7 , \\ 426069 Izhevsk, Russia E-mail: lag@istu.ru, abramov@istu.ru, nikitin@istu.ru \\ ${ }^{2}$ Institute of Applied Informatics, Automation and Mathematics, Faculty of Materials Science and Technology, Slovak University of \\ Technology, Hajdóczyho 1, 91724 Trnava, Slovakia E-mail: pavol.bozek@stuba.sk
}

The design of elliptic trajectories of kinematic mechanisms by classical method is a challenge. New method is proposed. Theoretical tests were conducted on a method. It can not be used for scaling and rotation. Some limitations are revealed as well. Geometric modeling showed the method can be applied to arbitrary curves. It should be noted that the theoretical and modeling researches of arbitary curves is not full. Simple robot was designed for processing ellipses. The design of the stand was assembled from aluminum profiles, linear modules and fasteners RK Rose + Krieger. Experiments have shown a difference between the theoretical and actual trajectory less than $5 \%$. The error of stationing was $8,5 \%$ before using of the direct analytical method.

Keywords: Kinematic mechanisms, Geometry, Calculation of trajectory, Arbitrary curves

\section{Acknowledgement}

Supported by Minobrnauki of Russian Federation, Grant GZ/TVG(01.10).

\section{References}

[1] LOZHKIN, A.G. (2009) Applied planemetry with singular transformations, IE UrO RAS, Ekaterinburg.

[2] LOZHKIN, A., DYUKINA, N. (2012) Structurization of analytical geometry on the base of symmetries, LAP, Saarbruken.

[3] EFIMOV N.V. (1967) Quadratic forms and matrices, Science, Moscow.

[4] BOŽEK, P., TURYGIN, Y. (2014) Measurement of the operating parameters and numerical analysis of the mechanical subsystem. Measurement Science Review, ISSN 1335-8871. - Vol. 14, No. 4 pp.198-203

[5] BIAGIOTTI, L., MELCHIORRI, C. (2008) Trajectory Planning for Automatic Machines and Robots. Springer, Science \& Business Media.

[6] BOŽEK, P., PIVARČIOVÁ, E. (2012) Registration of Holographic Images Based on Integral Transformation. In: Computing and Informatics. - ISSN 1335-9150. - Vol. 31, No. 6 s. 1369-1383

[7] GMITERKO, A., VIRGALA, I. (2011) Simplified Model of the Snake Rectilinear motion, 9th IEEE International Symposium on Applied Machine Intelligence and Informatics, pp. 307 - 310

[8] NIKITIN, Y.R., ABRAMOV I.V. (2010) CNC machines diagnostics, Proceedings 13-th International Simposium on Mechatronics, pp. 89-91, Trenčinske Teplice.

[9] TREFILOV, S.A., KALINKIN, A.A., NIKITIN, Y.R. (2007) High-maneuverable transport robot, University Review, Vol. 1, No 2, , pp. 34-39, Alexander Dubcek University of Trencin, Slovakia, Izhevsk State Technical University, Russia.

[10] LOZHKIN, A. (2010) About definition of singular transformation by N.V. Efimov, Geometry, topology, algebra and number theory, applications. Abst. of International conference dedicate to the 120th anniversary of B.N. Delone, pp. 160-162, Steklov MI RAS, Lomonosov MSU, Moscow.

[11] GIBSON, C.G. (2001) Elementary geometry of differentiable curves: an undergraduate introduction, University press, Cambridge.

[12] QIUJING, Z., CHUNHUA, W., JINGRU, S., SICHUN, D., (2011) A new type of current conveyor and its application in fully balanced diferential current-mode elliptic filterdesign. Journal of Electrical Engineering, Vol 62, ISSN 1335-3632, pp.126-133 